\title{
From design to implementation - The Joint Asia Diabetes Evaluation (JADE) program: A descriptive report of an electronic web-based diabetes management program
}

\author{
Gary T Ko 1,2, Wing-Yee So2, Peter C Tong2 ${ }^{2}$ Francois Le Coguiec ${ }^{3}$, Debborah Kerr³, Greg Lyubomirsky³, Beaver Tamesis³, \\ Troels Wolthers ${ }^{3}$, Jennifer Nan ${ }^{1}$ and Juliana Chan*1,2
}

\begin{abstract}
Background: The Joint Asia Diabetes Evaluation (JADE) Program is a web-based program incorporating a comprehensive risk engine, care protocols, and clinical decision support to improve ambulatory diabetes care.

Methods: The JADE Program uses information technology to facilitate healthcare professionals to create a diabetes registry and to deliver an evidence-based care and education protocol tailored to patients' risk profiles. With written informed consent from participating patients and care providers, all data are anonymized and stored in a databank to establish an Asian Diabetes Database for research and publication purpose.

Results: The JADE electronic portal (e-portal: http://www.jade-adf.org) is implemented as a Java application using the Apache web server, the mySQL database and the Cocoon framework. The JADE e-portal comprises a risk engine which predicts 5-year probability of major clinical events based on parameters collected during an annual comprehensive assessment. Based on this risk stratification, the JADE e-portal recommends a care protocol tailored to these risk levels with decision support triggered by various risk factors. Apart from establishing a registry for quality assurance and data tracking, the JADE e-portal also displays trends of risk factor control at each visit to promote doctor-patient dialogues and to empower both parties to make informed decisions.
\end{abstract}

Conclusions: The JADE Program is a prototype using information technology to facilitate implementation of a comprehensive care model, as recommended by the International Diabetes Federation. It also enables health care teams to record, manage, track and analyze the clinical course and outcomes of people with diabetes.

\section{Background}

In this pandemic of diabetes, Asia has the highest number of affected individuals with a disproportionate increase in the young to middle aged group $[1,2]$. Although diabetes reduces life expectancy by an average of 10-12 years [3], diabetes and associated complications are highly preventable and treatable [4-7]. Using a comprehensive diabetes registry established since 1995, our group has developed a series of risk equations [8-14] to predict all-cause death and cardiovascular-renal outcomes in Chinese type 2 dia-

* Correspondence: jchan@cuhk.edu.hk

1 Asia Diabetes Foundation, Flat 4B, Block B, Prince of Wales Hospital, Shatin, Hong Kong SAR, China

Full list of author information is available at the end of the article betic patients. Our group and others have also reported $50-70 \%$ risk reduction in these clinical outcomes amongst patients receiving protocol-driven care delivered by a multidisciplinary team compared to usual care [15-20].

In 2006, we developed a web-based Joint Asia Diabetes Evaluation (JADE) Program to combine the concepts of risk stratification and protocol-driven care to translate evidence to practice using information technology. In the past years, various computerized systems have been developed to facilitate management of diabetes or cardiovascular disease [21-26]. Most of the systems were data registries though some of them incorporated clinical practice guidelines and/or performance feedback. However, a comprehensive and easily accessible electronic sys- 
tem which integrates primary and secondary care with decision support, risk stratification and interactive feedback, as recommended by the International Diabetes Federation [27], is still lacking. In this program, we used an electronic portal (e-portal) to facilitate health care team to implement evidence-based care protocol and empower patients to improve self management. The administration of the Program is supported by a multidisciplinary team including a part-time endocrinologist, programmer, project coordinator. The e-portal is designed specifically to cater the needs of Asian countries in terms of language and risk equations which stratify patients into 4 care levels to guide clinical management, although these features can be easily adapted for other populations. The e-portal also generates concise graphic reports for both patients and physicians highlighting trends of "ABC" targets (i.e. glycated hemoglobin $\left[\mathrm{HbA}_{1 \mathrm{c}}\right]$, blood pressure $[\mathrm{BP}]$ and low-density lipoprotein cholesterol [LDL-C]) to facilitate individualizing treatment. We have reported the internal validation of the JADE Risk Engine [28] using a registry consisting of 7534 type 2 diabetic patients. Herein, we report the technical details of the design and implementation of this web-based program.

\section{Results}

The JADE portal is available to registered users since November 2007. In this early phase of implementation, we have limited the number of users by invitation to gain feedback, assess need of technical support and refine the Program. Eleven Key Opinion leaders from 8 countries or areas in Asia (China, Hong Kong, Taiwan, Singapore, Malaysia, Thailand, Philippines and Korea) were invited to form a Steering Committee. These steering committee members recommended appropriate clinicians in their countries to the JADE Portal Support Office (PSO). After registration, these clinicians were granted a log-in account with password.

\section{JADE e-portal http://www.jade-adf.org}

Figure 1 summarizes the key features of the JADE e-portal as a Java application using the Apache web server, the mySQL database and the Cocoon framework. The user input is validated both on the server-side and client-side, which is aligned with industry best coding practices. The validation technique prevents attackers from inserting potentially harmful syntax into the web application, which could then potentially be sent to the application server or backend database residing inside the network infrastructure. The system was developed in a secure manner and externally assessed by Cybertrust Inc. Through SQL injection, cross-site scripting and parameter manipulation, it was unable to gain session hijacking and authentication bypass.
The JADE e-portal includes a validated risk engine for risk stratification based on data collected during the annual comprehensive assessment. Based on the patient's risk level, a care protocol is recommended with clinical decision and self management support. The e-portal also provides user-friendly templates to guide users to collect relevant clinical data during the annual comprehensive assessment visit including eye and foot examination, blood and urine tests, medications, major medical events and quality of life. The British National Formulary was used as a framework to classify medications for data capture and future analysis.

At each review visit, key parameters as recommended by international guidelines are captured to document clinical progress. These include BP, body weight, risk factor control (e.g. $\mathrm{HbA}_{1 \mathrm{c}}$, lipid, renal function, albuminuria), self care, hypoglycemia and admissions since last visit (Figure 2, showing the comprehensive assessment webpage). These data can be collected on line at point-ofcare, or offline using paper format followed by date entry to the e-portal at a later stage, depending on the clinic set up and operation. All patients are given unique identification codes and each visit is dated to avoid double entry. All data are locked 12 weeks after the input to prevent 'back-date' data manipulation. However, through request to the PSO with clear explanation, unlocking of the relevant data for editing or deletion is possible. The timing of 12 weeks for data locking was selected since this was the average turnover time for return of laboratory results and data input in various Asian countries.

Based on results estimated by the JADE Risk Engine, the e-portal displays the 5-year probability of major clinical events which can be adjusted by changing values of modifiable risk factors to promote discussions between patients and care providers (Figure 3). Data collected at each review visit are displayed to show the trends of control of modifiable risk factors including $\mathrm{BP}, \mathrm{HbA}_{1 \mathrm{c}}$, LDL$\mathrm{C}$ and body weight. General recommendations can be triggered by predefined levels of risk factors to prompt care providers and patients to take appropriate actions. Printable reports showing risk predictions, trends of risk factor control and practice tips can be generated for care providers (in English) and patients (in 5 different Asian languages i.e. English, Thai, Korean, Malay and Chinese [both traditional and simplified Chinese]) for record purpose (Figure 4). Furthermore, the portal provides matrixes to help doctors monitor patients' levels of adherence to care processes (e.g. annual assessment, review visits, education sessions, laboratory tests) and self management as well as their status of attainment of treatment targets. These targets can be modified depending on the evolution of international healthcare standards. 


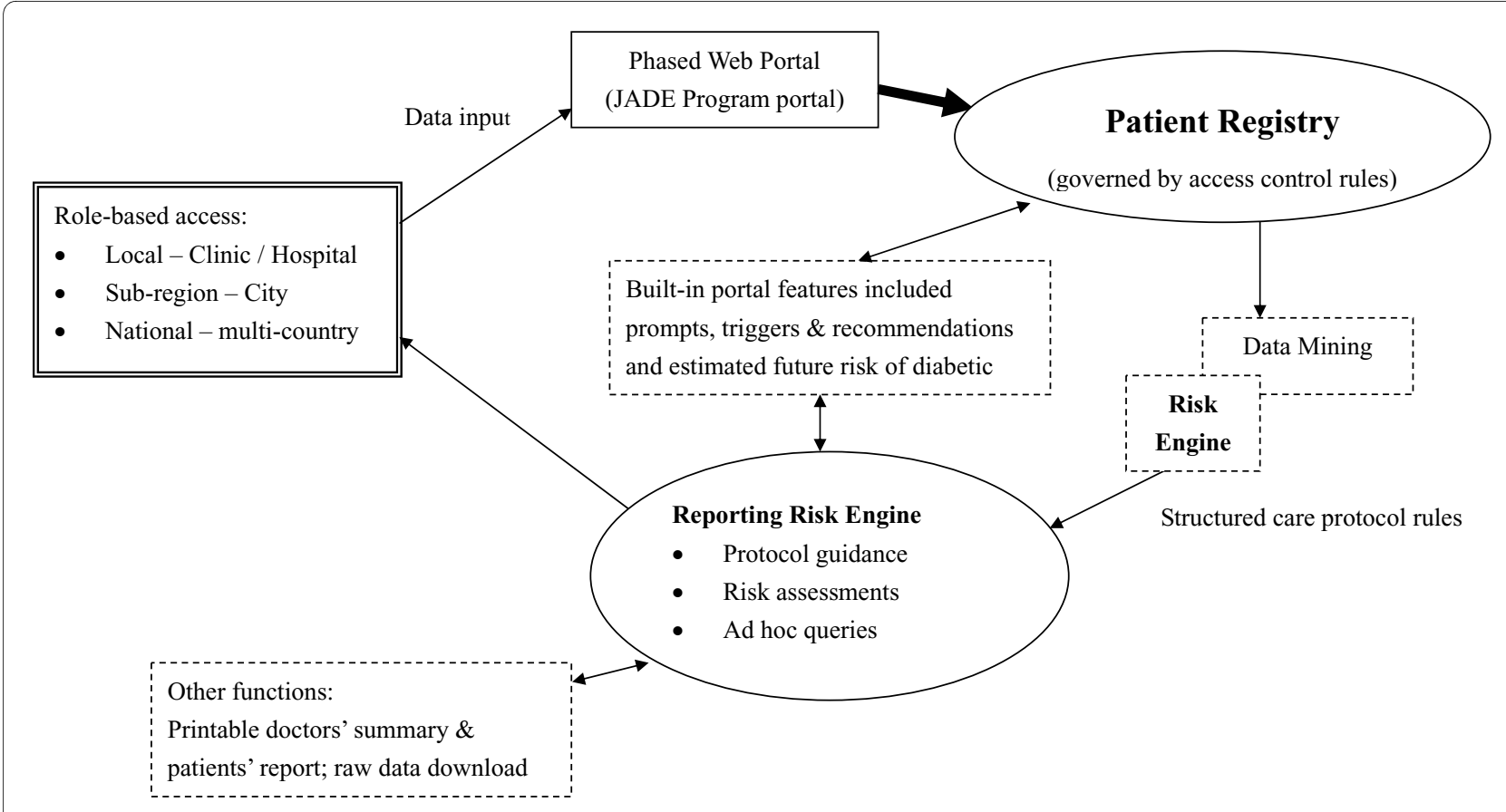

Figure 1 Logistics and components of the web-based electronic portal of the JADE Program.

Up to $1^{\text {st }}$ January 2010, 10,164 patients from Hong Kong, Taiwan, Singapore, Thailand, Philippines, Korea, India and Brunei have joined the JADE Program. The Program is scheduled to be launched in Mainland China in mid 2010.

\section{Discussion}

Although optimal management of risk factors and treatment to targets can substantially reduce risk of diabetic complications [4-6,29-32], there are multiple barriers at the system, care providers and patients' levels to translate these evidence to clinical practice. These include the complex nature of care protocols, need to interpret large amount of interrelated clinical information, demands on patients' self discipline as well as lack of time and resources for counseling and reinforcement of compliance. In most national or international surveys, standards of diabetes care remain suboptimal often due to low adherence to treatment guidelines and clinical inertia on the part of care providers and low levels of compliance with drugs and self care by patients [33-37].

Motivated by improved risk factor control and clinical outcomes in patients randomized to clinical trials [18,38], our group and others have demonstrated that delivery of protocol-driven care using a multidisciplinary team with particular focus on risk stratification, periodic assessments, treatment to target and reinforcement of treatment compliance including use of telephone counseling can reduce risk of all-cause death and cardio-renal outcomes by $50-70 \%[6,17-19,33,38-41]$.
Using these prototypes of care models as templates and through private-public partnerships, we used state of the art information technology to develop the JADE Program as a regional quality improvement program. We also used this virtual platform to promote collective learning and sharing of best practices based on evidence pertinent to Asian populations. The latter include the lower cutoff values for body mass index and waist circumference to define overweight/obesity as well as the high predictive values of renal function, albuminuria and low blood hemoglobin for cardiovascular disease. The JADE Program also displays trend lines with prompts and recommendations to reinforce key messages and empower patients and care providers to make informed decisions. Most importantly, health care teams can use the JADE eportal to create its own diabetes registry to detect defaults, monitor clinical progress and track key performance indexes (e.g. attainment of treatment targets) of their patients for continuous quality improvement.

Supported by the JADE Project team and the Steering Committee, the JADE Program also provides a virtual platform to promote collaborative research to address epidemiological and therapeutic questions pertinent to Asian populations. The establishment of the Asia Diabetes Database using the JADE e-portal aims to refine the accuracy and applicability of various risk equations to different Asian populations. By recording essential clinical data on an ongoing basis as recommended by international guidelines, the impact of adherence to medications and care processes by patients (e.g. self blood glucose 


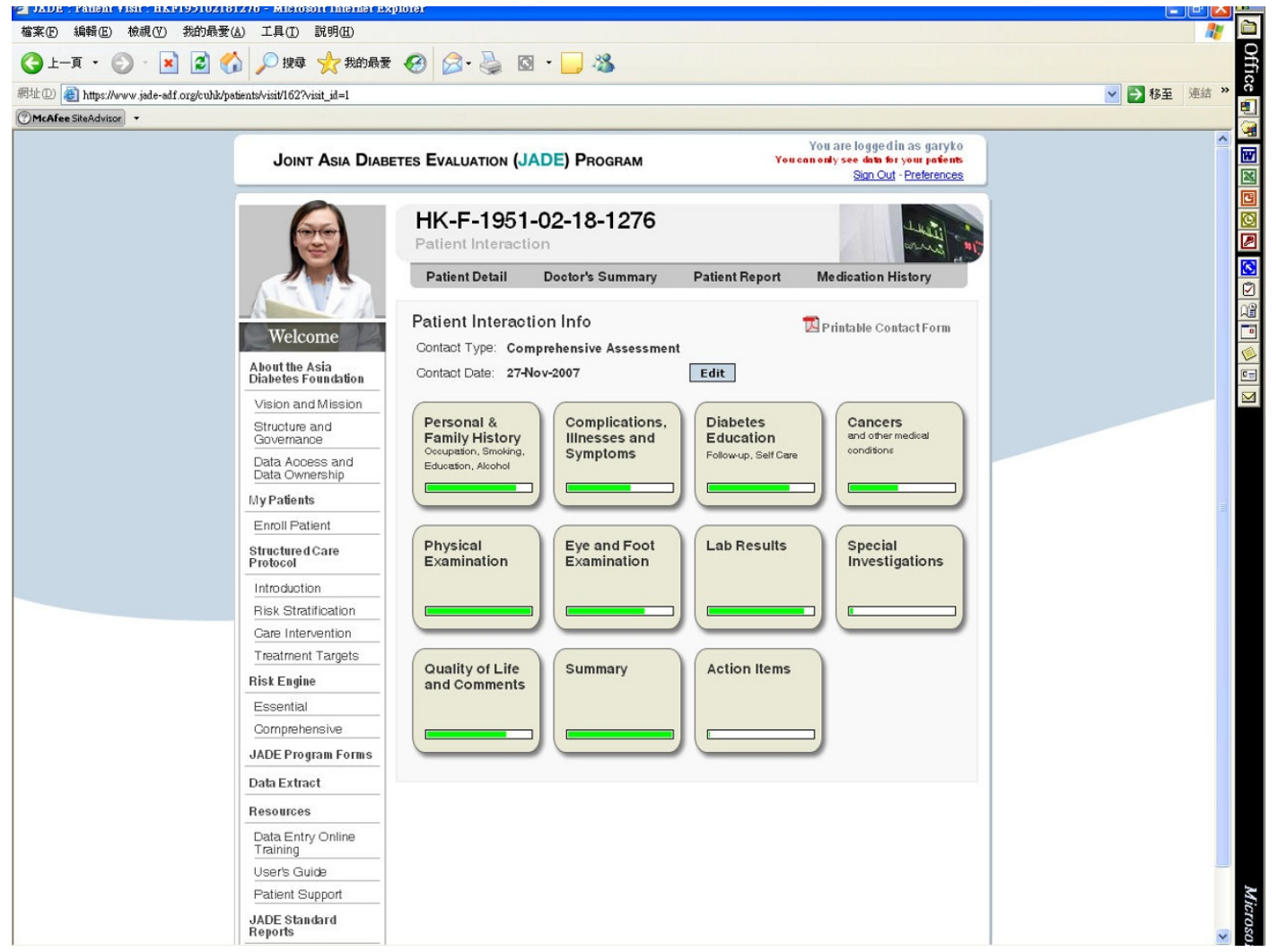

Figure 2 The JADE electronic portal provides templates to guide users to collect relevant data during the annual comprehensive assessment.

monitoring) and care providers (e.g. annual assessment and laboratory investigations); use of non-pharmacological (e.g. diabetes education, lifestyle modification) and pharmacological interventions as well as their interactions with various phenotypes and secular changes on clinical outcomes can be monitored and analyzed [42-44].

\section{Limitations}

The JADE Program is designed for diabetes and associated conditions and complications. It is disease specific that limits its application in non-diabetic subjects. However, diabetes is common and complex, for which a specific and comprehensive management tool is indicated. In addition to using graphic reports to motivate self management, there are rooms for further improvement such as education on appropriate drug use and medication adherence. Continuous review of the e-portal in terms of user-acceptability and recommendations based on evolving evidence is the major task of the JADE Project team. Of note, in order to fully utilize the features of the JADE e-portal, there is a need to modify the clinic practice to deploy trained non-medical personnel, e.g. nurses and physician assistants (e.g. high school or university graduates) to perform clinical assessments, enter data and remind doctors and patients to adhere to recommended treatments or procedures. Currently the JADE Project team is organizing a 1-2 day training program to share experience with health care teams on how to reorganize the clinic setting in order to use the e-portal more effectively using a multidisciplinary care model. Given the complex nature of diabetes and pluralistic needs of those affected, in spite of the state of the art information technology, a competent and caring clinical team remains the essence of quality diabetes care $[21,45,46]$.

\section{Conclusions}

We combined the concept of risk stratification and multidisciplinary care to use information technology to facilitate implementation of evidence-based diabetes care protocols. Using a multidisciplinary approach, doctors can use the JADE e-portal to reorganize the process of care delivery and establish a diabetes registry to manage, track and analyze the large amount of clinical information to improve decision making. On a research front, the 


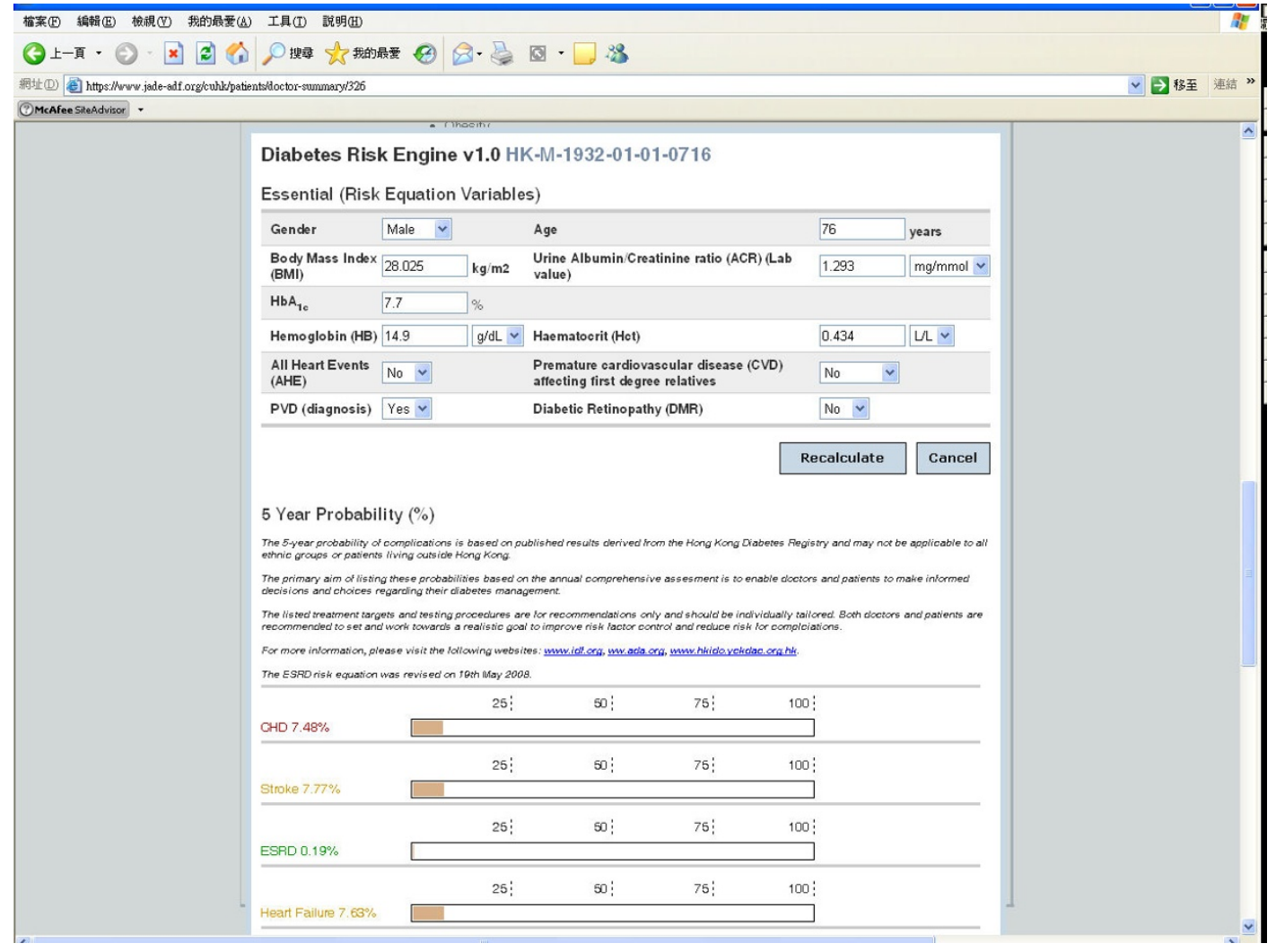

Figure 3 The JADE Risk Engine estimates the 5-year probability of major clinical events

JADE Program provides a virtual platform to collect epidemiological data and implement disease management programs to improve our understanding of the natural history of diabetes and evaluate effectiveness of various intervention in a pragmatic, naturalistic and scientific setting.

\section{Methods}

\section{Objective and Design of the JADE Program}

The objective of the JADE Program is to use information technology to facilitate health care team to deliver high quality diabetes care so as to reduce complication rates and improve self care. Figure 1 summarizes the logistics and components of the JADE e-portal including rolebased access rules, a risk engine, a diabetes registry and care protocols with reporting function. All enrolled patients gave written informed consent to submit their anonymized data for joint analysis. These data include clinical and demographic information and laboratory investigations during regular comprehensive assessments and regular follow-up visits. All participating doctors gave written informed consent and indicated their understanding of the rationale, purpose and implementation process of the JADE Program. This JADE e-portal is available on the internet and targeted at both specialists or primary care doctors who look after diabetic patients in solo practice, public health institutions, health maintenance organizations (HMO) or non-government organizations (NGO).

\section{Risk Stratification and Care Management Level}

The risk stratification program was based on 4 clinical parameters: 1) stratification parameters such as smoking status; 2) estimated glomerular filtration rates (eGFR); 3 ) risk scores derived from the Hong Kong Diabetes Registry Risk Equations; and 4) the existence of any known cardiovascular-renal complications (table 1) [8-14,27,28,4750]. The internal validation of this risk stratification program has been reported [28]. In brief, based on these 4 sets of parameters collected during an annual comprehensive assessment, patients can be categorized into one of the 4 care levels: 1 ) Very High Risk (VHR) group with clinically evident cardiovascular-renal complications; 2 ) High Risk (HR) group with 3 or more stratification parameters, or values above the high specificity cutoff for any one of the risk scores, or eGFR $<60 \mathrm{ml} / \mathrm{min} / 1.73 \mathrm{~m}^{2}$; 


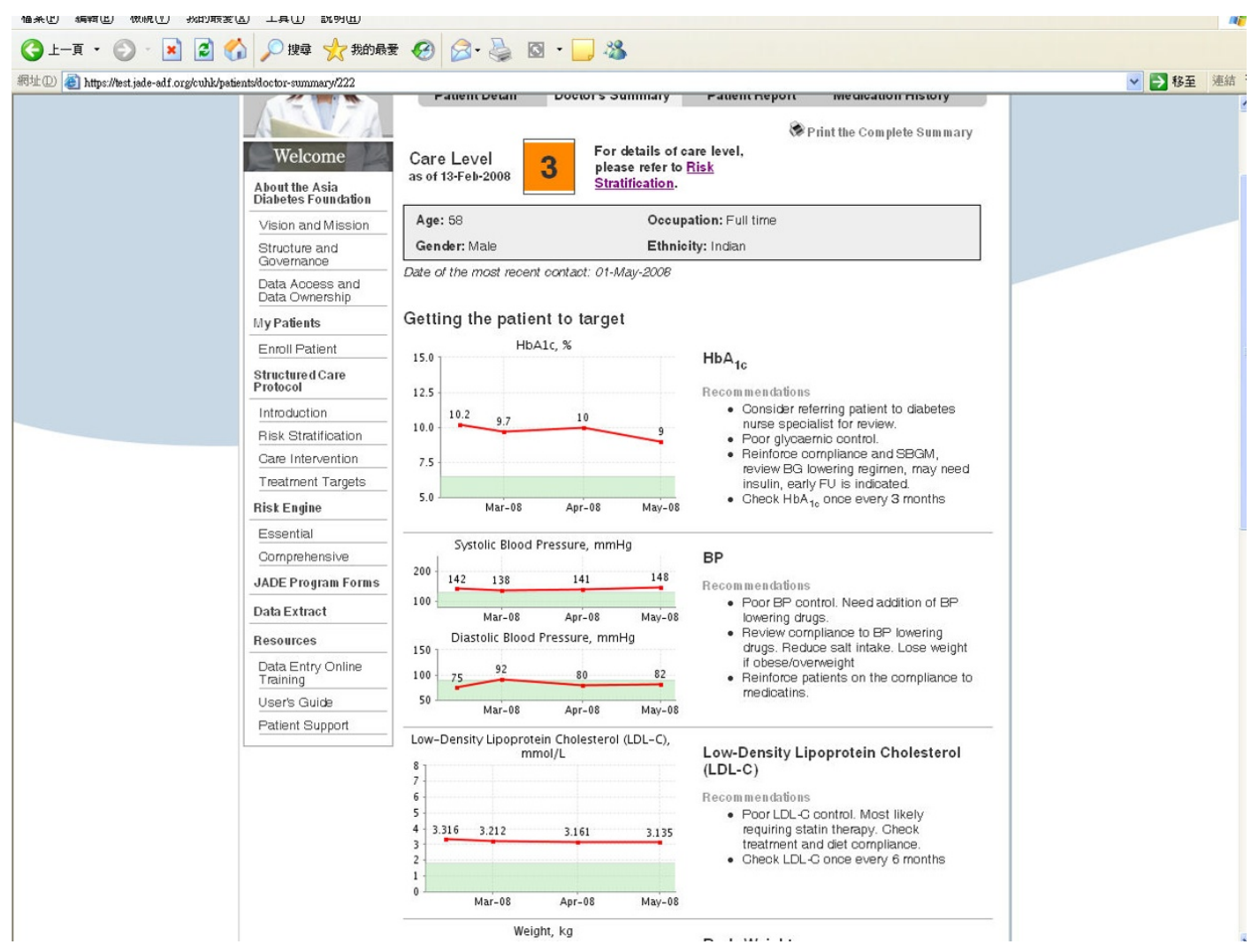

Figure 4 The JADE e-portal displays the risk level of the patients, supplemented by decision and self management support triggered by various risk factors which can be printed in 5 Asian languages

3) Medium Risk (MR) group with 2 stratification parameters, and/or values above the high sensitivity cutoff but lower than the high specificity cutoff for any of the risk scores, and/or eGFR between 60 and $90 \mathrm{ml} / \mathrm{min} / 1.73 \mathrm{~m}^{2}$; and 4) Low Risk (LR) group with one or fewer stratification parameter, and values below the high sensitivity cutoff for all risk scores, and eGFR $\geq 90 \mathrm{ml} / \mathrm{min} / 1.73 \mathrm{~m}^{2}$.

Based on these risk levels, a care protocol with predefined schedules and decision support is recommended [28]. Depending on the risk level, the e-portal will recommend intervals between review visits, laboratory tests and complication assessments. The risk level is estimated based on a comprehensive set of data collected at presentation and then 12-24 monthly thereafter for quality assurance and re-evaluation of risk level. Hence, the risk level, and corresponding management plan, may change according to the clinical status to promote cost-effective use of finite resources. Using charts and trend lines, physicians are encouraged to individualize therapies based on patients' profile and trend of 'ABC' targets to promote self care and reduce clinical inertia. The value of early intervention is now clearly confirmed by the legacy effect of attaining glycemic control early to reduce risk of future complications [7]. Although similar legacy effect has not been confirmed for dyslipidemia and blood pressure [51], optimal treatment of these conditions has been shown to reduce cardio-renal complications in both primary and secondary prevention [6].

\section{Self management support}

The JADE e-portal generates patients' report in simple layman terms and displays the trends of $\mathrm{HbA}_{1 \mathrm{c}}, \mathrm{BP}$ and LDL-C in diagrammatic forms. There are also prompts and practice tips on lifestyle and use of medication to achieve recommended treatment targets (i.e. $\mathrm{HbA}_{1 \mathrm{c}}<7 \%$, $\mathrm{BP}<130 / 80 \mathrm{mmHg}$, LDL-C $<2.6 \mathrm{mmol} / \mathrm{L})[27,28,49,50]$. At each visit, the e-portal re-estimates the 5-year probability of cardio-renal complications using the most updated clinical information of the patient, notably, risk factors which are modifiable. To this end, there is evidence suggesting that awareness of complications, health literacy [52] self efficacy and expectation of improved clinical outcomes [53] are associated with improved metabolic control and self care in diabetic patients. While the 
Table 1: Parameters used in the Joint Asia Diabetes Evaluation (JADE) electronic portal to derive the Care Management Level in Type 2 Diabetic Patients.

\begin{tabular}{|c|c|}
\hline Derivation parameters & Details \\
\hline $\begin{array}{l}\text { 1. Clinically evident } \\
\text { cardiovascular-renal } \\
\text { complications }\end{array}$ & $\begin{array}{l}\text { History of stroke, coronary heart disease, non-fatal heart failure, peripheral vascular disease, end stage } \\
\text { renal disease (dialysis or eGFR }<15 \mathrm{ml} / \mathrm{min} / 1.73 \mathrm{~m}^{2} \text { ) }\end{array}$ \\
\hline $\begin{array}{l}\text { 2. Risk stratification } \\
\text { parameters }\end{array}$ & $\begin{array}{l}\text { Current or ex smoker } \\
\mathrm{BMI} \geq 27.5 \mathrm{~kg} / \mathrm{m}^{2} \text { or waist circumference } \geq 80 \mathrm{~cm} \text { in women or } \geq 90 \mathrm{~cm} \text { in men } \\
\text { Blood pressure }>130 / 80 \mathrm{mmHg} \text { or treatment with anti-hypertensive drugs } \\
\mathrm{LDL}-\mathrm{C}>2.5 \mathrm{mmol} / \mathrm{l} \\
\mathrm{TG} \geq 2.3 \mathrm{mmol} / \mathrm{I} \& / \mathrm{or} \mathrm{HDL}-\mathrm{C}<1 \mathrm{mmol} / \mathrm{I} \\
\text { Treatment with lipid regulating drugs if } \mathrm{LDL}-\mathrm{C} \leq 2.5 \mathrm{mmol} / \mathrm{l} \text { and } \mathrm{TG}<2.3 \mathrm{mmol} / \mathrm{l} \text { and } \mathrm{HDL}-\mathrm{C} \geq 1.0 \mathrm{mmol} / \mathrm{I} \\
\text { Spot morning urine for ACR }>3.5 \mathrm{mg} / \mathrm{mmol} \text { in women or }>2.5 \mathrm{mg} / \mathrm{mmol} \text { in men } \\
\text { Foot at risk defined by } 2 \text { of } 3 \text { of the following: sensory neuropathy, skin changes (e.g. fungal infection, dry } \\
\text { skin) or deformities (e.g. claw feet or hallux deformities) } \\
\text { Retinopathy } \\
\mathrm{HbA}_{1 \mathrm{C}} \geq 8 \%\end{array}$ \\
\hline $\begin{array}{l}\text { 3. Hong Kong Diabetes } \\
\text { Registry Risk Scores }\end{array}$ & $\begin{array}{l}\text { High sensitivity and specificity cutoff points for various clinical endpoints (stroke, coronary heart disease, } \\
\text { end stage renal disease and heart failure) }\end{array}$ \\
\hline 4. Renal function & eGFR by the MDRD equation \\
\hline
\end{tabular}

JADE Program uses care level and risk prediction to empower patients, additional input by the health team will be needed, e.g. referral to dietitians or nurse educators or drug titration or change of medications.

\section{Governance, technical support and data security}

The JADE Program is governed by the Board of Directors of the Asia Diabetes Foundation (ADF) which is a nonprofit making organization incorporated under the Chinese University of Hong Kong (CUHK) Foundation. It is a charitable body approved by the Tax and Revenue Department of the Hong Kong Government with a mission to promote awareness and facilitate academic research to improve chronic disease management including diabetes. Hitherto, access to the JADE e-portal is by invitation and free of charge. The ownership and liability of the Program as well as all collected data and subsequent deliverables including publications belong to the ADF.

On an academic front, the JADE Steering Committee consists of leading diabetologists from Asia who provide overall direction and monitor progress of the Program. Members of the JADE Steering Committee also serve as local champions to promote the adoption of the JADE Program in their country. The JADE Project team consists of a medical director working closely with the Information Technology Team, PSO and a supporting team in each participating country.
To limit the impact of potential exposure or leakage of patient information, the JADE Program does not store any identifying patient information electronically. No name or national identity number is captured and a casespecific code (ADF code) is generated for each enrolled patient. Only the physician has the information to identify the patient given a specific ADF code. These case sensitive codes are known to the patients and all report forms generated electronically or in paper form, are kept by the physicians or in the case records as appropriate. Registered users, who are usually the doctor in charge of the clinic, can grant access rights to other clinic staff. These assistant personnel need to provide written consent and abide to the terms of reference of ADF before they can use the e-portal and have access to these anonymized data which can be decoded using the patient log kept at the clinic. At the time of writing, patients are given printed reports which summarize their risk levels, 5 -year risk of major events and key clinical parameters. They do not have access to their raw data electronically, although this feature can be incorporated at a later stage, depending on the uptake of the Program.

All data are given a 'reasonable' range for acceptance and will generate a prompt if data are above or below the range. The validity of all clinical information is checked periodically by a monitoring team designated by the JADE Project team to ensure the quality and integrity of these data for analysis purpose. While the monitor can- 
not change any data, he/she can flag reminders to the local supporting team when suspicious data is encountered such as large discrepancy in body mass index and waist circumference. For errors noted after the data has been locked, the corresponding user can request data unlocking for amendment. All editing activities are tracked and recorded by the PSO.

Apart from using anonymized data, the JADE e-portal also adopts the strictest security industry practices. These include end-to-end data encryption of the grade used by most online banking sites, user authentication, information access control mechanisms, and dedicated server hosting with physical access control to the facilities. In July 2007, Cybertrust Inc., an established and specialized security company, was commissioned to perform an independent security assessment of the application of the JADE e-portal. Cybertrust conducted both black box and white box security testing of the application, and verified that the JADE e-portal performed reliably and securely when tested with automated and manual attack techniques.

\section{Institutional board review and ethics approval}

The establishment of the Asia Diabetes Database using the JADE e-portal was approved by the Clinical Research Ethics Committee of the Chinese University of Hong Kong. Implementation of the JADE Program was also approved by the relevant institutional review board in individual countries through submission by the Steering Committee members. All patients were given detailed information sheet on the background, purpose and processes of the JADE Program. Written consent was obtained from each participant to undergo comprehensive assessment at enrolment and at regular intervals thereafter. Participating doctors and care providers also gave written informed consent indicating their understanding and willingness to promulgate the vision and mission of the JADE Program to improve ambulatory diabetes care.

\section{Portal Support Office (PSO)}

The Information Technology team based at the JADE PSO supports all program-related technical and logistic matters encountered by the users. The PSO organizes meetings with the JADE supporting teams in different countries on a regular basis to collect feedback and explain changes to the e-portal, as appropriate. All users are provided a manual of frequently asked question (FAQ) about the JADE e-portal. The PSO also provides information on evidence-based management plan of updated versions, scheduled maintenance, bug reports and technical tips. The service commitment in supporting on-line enquiry of the PSO include response time in 2 working days and resolution time in 2 to 7 days depending on complexity of the enquiries.

\section{Authors' contributions}

GK, WS, PT and JC conceptualised and designed the project. FC, DK and GL provided technical input throughout the project. GK and JC drafted the manuscript. WS, PT, GL, BT, TW and JN contributed to the intellectual content of the manuscript. All authors read and approved the final manuscript.

\section{Acknowledgements}

Special thanks are extended to the Steering Committee members for their support in launching and promulgating the vision and mission of the JADE Program in their respective countries: Professor Linong Ji (China), Professors KunHo Yoon and Jeong-Tack Woo (Korea), Dr. Fen-Lee Hew (Malaysia), Drs. Josephine Raboca and Leorino Sobrepena (Philippines), Drs. Chung-Horn Lee and Kevin Tan (Singapore), Professor Low-Tone Ho (Taiwan), Drs. Thep Himathong kam and Chaicharn Deerochanawong (Thailand). We thank Mr. Peter Chow for his invaluable contribution in making the JADE Program possible. The JADE Program was supported by the Chinese University of Hong Kong Foundation and an educational grant of MSD. Some of the authors (FC, DK, GL, BT and TW) are employees of MSD who have declared that they have no competing interests.

\section{Author Details}

${ }^{1}$ Asia Diabetes Foundation, Flat 4B, Block B, Prince of Wales Hospital, Shatin, Hong Kong SAR, China, 2Department of Medicine and Therapeutics, The Chinese University of Hong Kong, Prince of Wales Hospital, Hong Kong SAR, China and ${ }^{3}$ Merck Sharp \& Dohme (MSD), a subsidiary of Merck \& Co. Inc., USA

Received: 28 September 2009 Accepted: 13 May 2010

Published: 13 May 2010

\section{References}

1. Chan JC, MalikV, Jia W, Kadowaki T, Yajnik CS, Yoon KH, Hu FB: Diabetes in Asia: epidemiology, risk factors, and pathophysiology. JAMA 2009, 301(20):2129-2140.

2. Yoon KH, Lee JH, Kim JW, Cho JH, Choi YH, Ko SH, Zimmet P, Son HY: Epidemic obesity and type 2 diabetes in Asia. Lancet 2006, 368(9548):1681-1688.

3. Roglic G, Unwin N, Bennett PH, Mathers C, Tuomilehto J, Nag S, Connolly $\mathrm{V}$, King $\mathrm{H}$ : The burden of mortality attributable to diabetes: realistic estimates for the year 2000. Diabetes Care 2005, 28(9):2130-2135.

4. Brenner BM, Cooper ME, de Zeeuw D, Keane WF, Mitch WE, Parving HH, Remuzzi G, Snapinn SM, Zhang Z, Shahinfar S: Effects of losartan on renal and cardiovascular outcomes in patients with type 2 diabetes and nephropathy. N Engl J Med 2001, 345(12):861-869.

5. HPSCG: Heart Protection Study Collaborative Group (HPSCG). MRC/BHF Heart Protection Study of cholesterol lowering with simvastatin in 20,536 high-risk individuals: a randomised placebo-controlled trial. Lancet 2002, 360(9326):7-22.

6. Gaede $\mathrm{P}$, Lund-Andersen $\mathrm{H}$, Parving HH, Pedersen O: Effect of a multifactorial intervention on mortality in type 2 diabetes. NEngl J Med 2008, 358(6):580-591.

7. Holman RR, Paul SK, Bethel MA, Matthews DR, Neil HA: 10-year follow-up of intensive glucose control in type 2 diabetes. N Engl J Med 2008, 359(15):1577-1589.

8. So WY, Yang X, Ma RC, Kong AP, Lam CW, Ho CS, Cockram CS, Ko GT, Chow CC, Wong V, et al:: Risk factors in V-shaped risk associations with all-cause mortality in type 2 diabetes-The Hong Kong Diabetes Registry. Diabetes Metab Res Rev 2008, 24(3):238-246.

9. Yang X, So WY, Kong AP, Ho CS, Lam CW, Stevens RJ, Lyu RR, Yin DD, Cockram CS, Tong PC, et al:: Development and validation of stroke risk equation for Hong Kong Chinese patients with type 2 diabetes: the Hong Kong Diabetes Registry. Diabetes Care 2007, 30(1):65-70.

10. Yang X, So WY, Kong AP, Ma RC, Ko GT, Ho CS, Lam CW, Cockram CS, Chan JC, Tong PC: Development and validation of a total coronary heart disease risk score in type 2 diabetes mellitus. Am J Cardiol 2008, 101(5):596-601.

11. Yang XL, So WY, Kong AP, Ho CS, Lam CW, Ng MH, Lyu RR, Yin DD, Chow CC, Cockram CS, et al:: Modified end-stage renal disease risk score for 
Chinese type 2 diabetic patients--the Hong Kong Diabetes Registry. Diabetologia 2007, 50(6):1348-1350.

12. Yang X, So WY, Tong PC, Ma RC, Kong AP, Lam CW, Ho CS, Cockram CS, Ko GT, Chow CC, et al:: Development and validation of an all-cause mortality risk score in type 2 diabetes. Arch Intern Med 2008, 168(5):451-457.

13. Yang X, Ko GT, So WY, Ma RC, Yu LW, Kong AP, Zhao H, Chow CC, Tong PC, Chan JC: Associations of hyperglycemia and insulin usage with the risk of cancer in type 2 diabetes: the Hong Kong diabetes registry. Diabetes 2010, 59(5):1254-1260

14. Yang X, So WY, Ma RC, Ko GT, Kong AP, Zhao H, Luk AO, Lam CW, Ho CS, Tong PC, et al:: Low LDL cholesterol, albuminuria, and statins for the risk of cancer in type 2 diabetes: the Hong Kong diabetes registry. Diabetes Care 2009, 32(10):1826-1832

15. Chan JC, Cockram CS: Organization of diabetes care - Western Pacific Region (Hong Kong and China as example). In International Textbook of Diabetes Mellitus Third edition. Edited by: DeFronzo A, Feranninni E, Keen H, Zimmet P. John, Wiley \& Son; 2004.

16. Kong AP, Yang X, Ko GT, So WY, Chan WB, Ma RC, Ng VW, Chow CC, Cockram CS, Tong PC, et al.: Effects of treatment targets on subsequent cardiovascular events in Chinese patients with type 2 diabetes. Diabetes Care 2007, 30(4):953-959.

17. Leung WY, So WY, Tong PC, Chan NN, Chan JC: Effects of structured care by a pharmacist-diabetes specialist team in patients with type 2 diabetic nephropathy. Am J Med 2005, 118(12):1414.

18. So WY, Tong PC, Ko GT, Leung WY, Chow CC, Yeung VT, Chan WB, Critchley JA, Cockram CS, Chan JC: Effects of protocol-driven care versus usual outpatient clinic care on survival rates in patients with type 2 diabetes. Am J Manag Care 2003, 9(9):606-615.

19. Wu JY, Leung WY, Chang S, Lee B, Zee B, Tong PC, Chan JC: Effectiveness of telephone counselling by a pharmacist in reducing mortality in patients receiving polypharmacy: randomised controlled trial. $B M J$ 2006, 333(7567):522.

20. So WY, Chan JC: The role of the multidisciplinary team. In Textbook of Diabetes Edited by: Goldstein DB. Cockram CS: Blackwell; 2010 in press.

21. Baker AM, Lafata JE, Ward RE, Whitehouse F, Divine G: A Web-based diabetes care management support system. It Comm J Qual Improv 2001, 27(4):179-190.

22. Morris AD, Boyle DI, MacAlpine R, Emslie-Smith A, Jung RT, Newton RW, MacDonald TM: The diabetes audit and research in Tayside Scotland (DARTS) study: electronic record linkage to create a diabetes register. DARTS/MEMO Collaboration. BMJ 1997, 315(7107):524-528.

23. Selby JV, Karter AJ, Ackerson LM, Ferrara A, Liu J: Developing a prediction rule from automated clinical databases to identify high-risk patients in a large population with diabetes. Diabetes Care 2001, 24(9):1547-1555.

24. Sonksen P, Williams C: Information technology in diabetes care 'Diabeta': 23 years of development and use of a computer-based record for diabetes care. Int J Biomed Comput 1996, 42(1-2):67-77.

25. Weber V, Bloom F, Pierdon S, Wood C: Employing the electronic health record to improve diabetes care: a multifaceted intervention in an integrated delivery system. J Gen Intern Med 2008, 23(4):379-382.

26. Wells S, Furness S, Rafter N, Horn E, Whittaker R, Stewart A, Moodabe K, Roseman P, Selak V, Bramley D, et al:: Integrated electronic decision support increases cardiovascular disease risk assessment four fold in routine primary care practice. Eur J Cardiovasc Prev Rehabil 2008, 15(2):173-178.

27. IDF: International Diabetes Federation (IDF) Clinical Guidelines Task Force. Global Guideline for Type 2 Diabetes: recommendations for standard, comprehensive, and minimal care. Diabet Med 2006, 23(6):579-593.

28. Chan JC, So WY, Ko GT, Tong PC, Yang X, Ma RC, Kong AP, Wong R, Le Coguiec F, Tamesis B, et al:: The Joint Asia Diabetes Evaluation (JADE) Program: A Web-based Program To Translate Evidence To Clinical Practice in Type 2 Diabetes. Diabet Med 2009, 26:693-699.

29. Parving HH, Lehnert H, Brochner-Mortensen J, Gomis R, Andersen S, Arner $P$ : The effect of irbesartan on the development of diabetic nephropathy in patients with type 2 diabetes. NEng/ J Med 2001, 345(12):870-878.

30. UKPDS: Intensive blood-glucose control with sulphonylureas or insulin compared with conventional treatment and risk of complications in patients with type 2 diabetes (UKPDS 33). UK Prospective Diabetes Study (UKPDS) Group. Lancet 1998, 352(9131):837-853.
31. UKPDS: Efficacy of atenolol and captopril in reducing risk of macrovascular and microvascular complications in type 2 diabetes: UKPDS 39. UK Prospective Diabetes Study Group. BMJ 1998, 317(7160):713-720

32. Yusuf S, Sleight P, Pogue J, Bosch J, Davies R, Dagenais G: Effects of an angiotensin-converting-enzyme inhibitor, ramipril, on cardiovascular events in high-risk patients. The Heart Outcomes Prevention Evaluation Study Investigators. N Engl J Med 2000, 342(3):145-153.

33. Chan JC, So WY, Yeung CY, Ko GT, Lau IT, Tsang MW, Lau KP, Siu SC, Li JK, Yeung VT, et al.: Effects of structured versus usual care on renal endpoint in type 2 diabetes: the SURE study: a randomized multicenter translational study. Diabetes Care 2009, 32(6):977-982.

34. Grol R, Grimshaw J: From best evidence to best practice: effective implementation of change in patients' care. Lancet 2003, 362(9391):1225-1230

35. Narayan KM, Gregg EW, Engelgau MM, Moore B, Thompson TJ, Williamson $D F$, Vinicor F: Translation research for chronic disease: the case of diabetes. Diabetes Care 2000, 23(12):1794-1798.

36. Saaddine JB, Cadwell B, Gregg EW, Engelgau MM, Vinicor F, Imperatore G, Narayan KM: Improvements in diabetes processes of care and intermediate outcomes: United States, 1988-2002. Ann Intern Med 2006, 144(7):465-474.

37. Saaddine JB, Engelgau MM, Beckles GL, Gregg EW, Thompson TJ, Narayan KM: A diabetes report card for the United States: quality of care in the 1990s. Ann Intern Med 2002, 136(8):565-574

38. Leung WY, So WY, Tong PC, Lo MK, Lee KF, Ko GT, Chan WB, Cockram CS, Brenner BM, Shahinfar S, et al:: The renoprotective effects of structured care in a clinical trial setting in type 2 diabetic patients with nephropathy. Nephrol Dial Transplant 2004, 19(10):2519-2525.

39. Chan JC, Gagliardino JJ, Baik SH, Chantelot JM, Ferreira SR, Hancu N, Ilkova $H$, Ramachandran A, Aschner P: Multifaceted determinants for achieving glycemic control: the International Diabetes Management Practice Study (IDMPS). Diabetes Care 2009, 32(2):227-233.

40. Ma YC, Zuo L, Chen JH, Luo Q, Yu XQ, Li Y, Xu JS, Huang SM, Wang LN, Huang $W$, et al: Modified glomerular filtration rate estimating equation for Chinese patients with chronic kidney disease. J Am Soc Nephrol 2006, 17(10):2937-2944

41. Piatt GA, Orchard TJ, Emerson S, Simmons D, Songer TJ, Brooks MM Korytkowski M, Siminerio LM, Ahmad U, Zgibor JC: Translating the chronic care model into the community: results from a randomized controlled trial of a multifaceted diabetes care intervention. Diabetes Care 2006, 29(4):811-817.

42. Ko GT, So WY, Tong PC, Chan WB, Yang X, Ma RC, Kong AP, Ozaki R, Yeung CY, Chow CC, et al: Effect of interactions between C peptide levels and insulin treatment on clinical outcomes among patients with type 2 diabetes mellitus. CMAJ 2009, 180(9):919-926.

43. Luk AO, Yang X, Ma RC, Ng VW, Yu LW, Lau WW, Ozaki R, Chow FC, Kong AP, Tong PC, et al: Association of statin use and development of renal dysfunction in type 2 diabetes-The Hong Kong Diabetes Registry. Diabetes Res Clin Pract 2010 in press.

44. Tong PC, Ko GT, So WY, Chiang SC, Yang X, Kong AP, Ozaki R, Ma RC, Cockram CS, Chow CC, et al:: Use of anti-diabetic drugs and glycaemic control in type 2 diabetes-tThe Hong Kong Diabetes Registry. Diabetes Res Clin Pract 2008, 82(3):346-352.

45. Bu D, Pan E, Walker J, Adler-Milstein J, Kendrick D, Hook JM, Cusack CM Bates DW, Middleton B: Benefits of information technology-enabled diabetes management. Diabetes Care 2007, 30(5):1137-1142.

46. Green CJ, Fortin P, Maclure M, Macgregor A, Robinson S: Information system support as a critical success factor for chronic disease management: Necessary but not sufficient. Int J Med Inform 2006, 75(12):818-828

47. Yang X, Ma RC, So WY, Ko GT, Kong AP, Lam CW, Ho CS, Cockram CS, Wong VC, Tong PC, et al: Impacts of chronic kidney disease and albuminuria on associations between coronary heart disease and its traditional risk factors in type 2 diabetic patients - the Hong Kong diabetes registry. Cardiovasc Diabetol 2007, 6:37.

48. Yang XL, So WY, Kong AP, Clarke P, Ho CS, Lam CW, Ng MH, Lyu RR, Yin DD, Chow CC, et al:: End-stage renal disease risk equations for Hong Kong Chinese patients with type 2 diabetes: Hong Kong Diabetes Registry. Diabetologia 2006, 49(10):2299-2308.

49. ADA: American Diabetes Association (ADA). Clinical practice recommendations 2007. Diabetes Care 2007, 30(Suppl 1):S1-S103. 
50. APDPG: Asian-Pacific Type 2 Diabetes Policy Group (APDPG). In Type 2 diabetes practical targets and Treatment Singapore: International Diabetes Institute: Melbourne, and In vivo Communications (Asia) Pte Limited; 2005.

51. Holman RR, Paul SK, Bethel MA, Neil HA, Matthews DR: Long-term followup after tight control of blood pressure in type 2 diabetes. NEng/ J Med 2008, 359(15):1565-1576

52. Tang YH, Pang SM, Chan MF, Yeung GS, Yeung VT: Health literacy, complication awareness, and diabetic control in patients with type 2 diabetes mellitus. J Adv Nurs 2008, 62(1):74-83.

53. Wu SF, Courtney M, Edwards H, McDowell J, Shortridge-Baggett LM, Chang PJ: Self-efficacy, outcome expectations and self-care behaviour in people with type 2 diabetes in Taiwan. J Clin Nurs 2007, 16(11C):250-257.

\section{Pre-publication history}

The pre-publication history for this paper can be accessed here: http://www.biomedcentral.com/1472-6947/10/26/prepub

doi: $10.1186 / 1472-6947-10-26$

Cite this article as: Ko et al., From design to implementation - The Joint Asia

Diabetes Evaluation (JADE) program: A descriptive report of an electronic web-based diabetes management program BMC Medical Informatics and Decision Making 2010, 10:26

Submit your next manuscript to BioMed Central and take full advantage of:

- Convenient online submission

- Thorough peer review

- No space constraints or color figure charges

- Immediate publication on acceptance

- Inclusion in PubMed, CAS, Scopus and Google Scholar

- Research which is freely available for redistribution

Submit your manuscript at www.biomedcentral.com/submit
C) Biomed Central 